University of Nebraska - Lincoln

DigitalCommons@University of Nebraska - Lincoln

USGS Staff -- Published Research

US Geological Survey

4-1989

Simulation of Fractionation of 13C During Nonequilibrium Reactive Solute Transport in Geologic Systems: Formulation and Example Calculation

J. Noorishad

Lawrence Berkeley Laboratory

C.L. Carnahan

Lawrence Berkeley Laboratory

Larry Benson

University of Colorado at Boulder, great.basin666@gmail.com

Follow this and additional works at: http://digitalcommons.unl.edu/usgsstaffpub

Noorishad, J.; Carnahan, C.L.; and Benson, Larry, "Simulation of Fractionation of 13C During Nonequilibrium Reactive Solute Transport in Geologic Systems: Formulation and Example Calculation" (1989). USGS Staff -- Published Research. 800.

http:// digitalcommons.unl.edu/usgsstaffpub/800

This Article is brought to you for free and open access by the US Geological Survey at DigitalCommons@University of Nebraska - Lincoln. It has been accepted for inclusion in USGS Staff -- Published Research by an authorized administrator of DigitalCommons@University of Nebraska - Lincoln. 


\title{
Simulation of Fractionation of ${ }^{13} \mathrm{C}$ During Nonequilibrium Reactive Solute Transport in Geologic Systems: Formulation and Example Calculation
}

\author{
J. Noorishad and C. L. Carnahan \\ Earth Sciences Division, Lawrence Berkeley Laboratory, Berkeley, California \\ L. V. BENSON \\ U.S. Geological Survey, Denver, Colorado
}

\begin{abstract}
Equations of transport for the fractionating stable carbon isotope ${ }^{13} \mathrm{C}$ have been formulated and implemented in a nonequilibrium reactive chemical transport code. Application is demonstrated by solution of a generic problem. The new modeling capability adds a new dimension to investigation of groundwater evolution.
\end{abstract}

\section{INTRODUCTION}

Major factors affecting the chemical evolution of groundwater are the composition of recharging water, travel time to and within an aquifer, and chemical processes that occur during the transport. Studies of ${ }^{13} \mathrm{C}$ fractionation within an aquifer help to address some of these issues. For example, measurements of ${ }^{14} \mathrm{C}$ content of groundwater often are used to estimate relative groundwater ages. Interpretation of ${ }^{14} \mathrm{C}$ radiometric results may require correction to account for mixing of waters of different relative ages and for dilution of the ${ }^{14} \mathrm{C}$ content of groundwater by dissolution of radioactively "dead" carbonate rocks containing no ${ }^{14} \mathrm{C}$. Such correlations are assisted by knowledge of ${ }^{13} \mathrm{C} /{ }^{12} \mathrm{C}$ ratios and total carbonate contents of the mixing waters and of the dissolved carbonate rock [Pearson and Hanshaw, 1970; Wigley, 1975]. For another example, knowledge of ${ }^{13} \mathrm{C} /{ }^{12} \mathrm{C}$ ratios can help to define the processes (i.e., open versus closed system chemical reactions affecting the evolution of a carbonate groundwater between sampling points, especially in cases where availability of samples is limited spatially [Dienes et al., 1974]). Detailed description of carbonate groundwater evolution requires consideration of nonequilibrium processes affecting ${ }^{13} \mathrm{C} /{ }^{12} \mathrm{C}$ ratios. The purpose of this note is to provide the mathematical formulation of equations governing the variation of ${ }^{13} \mathrm{C} /{ }^{12} \mathrm{C}$ ratios arising from a nonequilibrium chemical reaction of flowing groundwater with carbonate rocks. The formulation has been implemented in the computer code CHMTRNS [Noorishad et al., 1987]. The approach is illustrated by an example calculation which has been chemically oversimplified deliberately in order to emphasize salient features of the method.

\section{FORMULATION}

Chemical reactions involving ${ }^{13} \mathrm{C}$-rich carbonate rocks will change the relative amounts of the isotopes ${ }^{13} \mathrm{C}$ and ${ }^{12} \mathrm{C}$ within individual carbonate aqueous species. These changes are expressed as changes of the isotopic ratio $R_{i}$ in species $i$, defined by

$$
R_{i}={ }^{13} C_{i} /{ }^{12} C_{i}
$$

Copyright 1989 by the American Geophysical Union. where the notation ${ }^{m} C_{i}$ denotes the concentration of that fraction of species $i$ containing the isotope of mass $m$. Changes of $R_{i}$ are measured by the isotopic shift $\delta_{1}$, defined by

$$
\delta_{i}=10^{3}\left(\frac{R_{i}}{R_{\mathrm{PDB}}}-1\right)
$$

where $\boldsymbol{R}_{\mathrm{PDB}}$ is the isotopic ratio of a standard.

To formulate the equations of change of isotopic composition during transport, we consider the aqueous species $\mathrm{CO}_{3}^{2-}, \mathrm{HCO}_{3}^{-}$, and $\mathrm{H}_{2} \mathrm{CO}_{3}^{0}$ and the solid $\mathrm{CaCO}_{3}$ (c) (calcite), and denote their respective concentrations by $C_{2}, C_{1}, C_{0}$, and $C_{s}$. The transport equation for these species is then

$$
L\left(C_{0}+C_{1}+C_{2}\right)+\frac{\partial C_{s}}{\partial t}=0
$$

where the operator $L$ is defined by

$$
L(\quad)=\frac{\partial}{\partial t}(\quad)+\nabla \cdot[(\quad) \nabla-D \nabla(\quad)]
$$

or

$$
L\left(C_{T}\right)+\frac{\partial C_{s}}{\partial t}=0
$$

where $C_{T}=C_{0}+C_{1}+C_{2}$. We can write, also,

$$
L\left({ }^{13} C_{0}+{ }^{13} C_{1}+{ }^{13} C_{2}\right)+\frac{\partial^{13} C_{S}}{\partial t}=0
$$

Because ${ }^{13} C_{i} \ll{ }^{12} C_{i}$, we have as a good approximation

$$
{ }^{13} C_{\mathrm{r}}=R_{i} C_{i} \quad i=0,1,2, s
$$

Also,

$$
R_{i}=R_{\mathrm{PDB}}\left(10^{-3} \delta_{i}+1\right)
$$

The net isotopic shift of the fluid $\delta_{\text {sol }}$ is defined by

$$
\sum_{i=0}^{2} C_{i} \delta_{i}=C_{T} \delta_{\mathrm{sol}}
$$

We adopt the calcite precipitation mechanism proposed by Plummer et al. [1978], in which $\mathrm{CaCO}_{3}$ (c) precipitates 
directly from $\mathrm{HCO}_{3}^{-}(\mathrm{aq})$. Then, substituting (3) and (4) into (2) and using (1) and (5) gives

$$
L\left(C_{T} \delta_{\text {sol }}\right)+\frac{\partial}{\partial t}\left(\delta_{x} C_{s}\right)=0
$$

where

Dissolution case

$$
\delta_{x}=\delta_{s} \quad \partial C_{s} / \partial t<0
$$

Precipitation case

$$
\delta_{x}=\delta_{1} \quad \partial C_{s} / \partial t>0
$$

In the case of dissolution, where carbonate from the rock is added to the mobile phase, (6) becomes

$$
L\left(C_{T} \delta_{\text {sol }}\right)+\delta_{s}\left(\partial C_{s} / \partial t\right)=0
$$

Combining (7) and (1) we obtain

$$
L\left(\theta_{d}\right)=0
$$

where

$$
\theta_{d}=\left(\delta_{\text {sol }}-\delta_{s}\right) C_{T}
$$

In the case of precipitation we can expand (6) to

$$
L\left(C_{T} \delta_{\mathrm{sol}}\right)+\delta_{1} \frac{\partial C_{s}}{\partial t}+C_{s} \frac{\partial \delta_{1}}{\partial t}=0
$$

The shift of the bicarbonate species $\delta_{1}$, originating from fractionation during dissolution of $\mathrm{CO}_{2}$ (gas) in water, can be referenced to $\delta_{\mathrm{CO}_{2}}$ in the following manner. We have

$$
R_{\mathrm{CO}_{2}}=R_{\mathrm{PDB}}\left(10^{-3} \delta_{\mathrm{CO}_{2}}+1\right)
$$

The partition coefficients $\alpha_{i}$ are defined by

$$
\alpha_{i}=R_{i} / R_{\mathrm{CO}_{2}} \quad i=0,1,2
$$

where $i$ refers to $\mathrm{H}_{2} \mathrm{CO}_{3}^{0}, \mathrm{HCO}_{3}^{-}$, and $\mathrm{CO}_{3}^{2-}$, respectively. Then using (4),

$$
\delta_{i}=\alpha_{i} \delta_{\mathrm{CO}_{2}}+10^{3}\left(\alpha_{i}-1\right) \quad i=0,1,2
$$

We can also reference the aqueous carbonate species to each other and eliminate $\delta_{\mathrm{CO}_{2}}$ from (10). If we choose $\mathrm{H}_{2} \mathrm{CO}_{3}^{0}(i=$ 0 ) as the reference species, we get

$$
\begin{aligned}
& \delta_{1}=\frac{\alpha_{1}}{\alpha_{0}} \delta_{0}+10^{3}\left(\frac{\alpha_{1}}{\alpha_{0}}-1\right)=A_{1} \delta_{0}+A_{2} \\
& \delta_{2}=\frac{\alpha_{2}}{\alpha_{0}} \delta_{0}+10^{3}\left(\frac{\alpha_{2}}{\alpha_{0}}-1\right)=A_{3} \delta_{0}+A_{4}
\end{aligned}
$$

Substituting (11a) and (11b) into (5) and solving for $\delta_{0}$ gives

$$
\begin{aligned}
\delta_{0} & =\frac{C_{T} \delta_{\text {sol }}-10^{3}\left\{C_{1}\left[\left(\alpha_{1} / \alpha_{0}\right)-1\right]+C_{2}\left[\left(\alpha_{2} / \alpha_{0}\right)-1\right]\right\}}{C_{0}+\left(\alpha_{1} / \alpha_{0}\right) C_{1}+\left(\alpha_{2} / \alpha_{0}\right) C_{2}} \\
& =\frac{C_{T} \delta_{\text {sol }}-A_{5}}{A_{6}}
\end{aligned}
$$

Defining $\theta_{p}=C_{T} \delta_{\text {sol }}$ and substituting (12) into (11a) we obtain

$$
\delta_{1}=\frac{A_{1}}{A_{6}} \theta_{p}-\left(\frac{A_{1} A_{5}}{A_{6}}-A_{2}\right)=A_{7} \theta_{p}+A_{8}
$$

where all $\boldsymbol{A}_{i}$ parameters are defined in terms of concentrations of carbonate species and $\alpha_{i}, i=0,1,2$. The latter partition coefficients are given [Deines et al., 1974] as functions of absolute temperature $T$ by

$$
\begin{aligned}
& \ln \alpha_{0}=-0.91 \times 10^{-3}+6.3 / T^{2} \\
& \ln \alpha_{1}=-4541 \times 10^{-3}+1099 / T^{2} \\
& \ln \alpha_{2}=-3.4 \times 10^{-3}+870 / T^{2}
\end{aligned}
$$

Substituting (13) into (9) results in

$$
L\left(\theta_{p}\right)+\left(A_{7} \theta_{p}+A_{8}\right) \frac{\partial C_{s}}{\partial t}+C_{s} \frac{\partial}{\partial t}\left(A_{7} \theta_{p}+A_{8}\right)=0
$$

Equations (8) and (14) are partial differential equations of transport for the new variables $\theta_{d}$ and $\theta_{p}$ that keep track of $\delta^{13} \mathrm{C}$ in the solution, in cases of dissolution or precipitation of calcite, respectively. Unlike (8), (14) is a nonlinear equation coupled to the other reactive transport equations through the dependence of the $A_{i}$ parameters on the concentrations of carbonate species.

\section{ALGORITHM IMPLEMENTATION}

With the formulation of the transport equations for the fractionating ${ }^{13} \mathrm{C}$, algorithm development is straightforward. This was implemented in the nonequilibrium reactive transport code CHMTRNS [Noorishad et al., 1987]. (CHMTRNS is based on the equilibrium reactive transport code CHEMTRN [Miller and Benson, 1983; Miller, 1983].) Mathematical verification of such works falls in the category of verification of reactive chemical transport computer codes. Code performance in solving hypothetical problems, intercode comparisons, and field or laboratory experimental verification attempts are steps that are taken, depending on the possibilities, to achieve this end. Stringent testing of the CHMTRNS code through many simulations, as reported elsewhere [Noorishad et al., 1987], has demonstrated that implementation of the transport equation for $\theta_{d}$ and $\theta_{p}$ in CHMTRNS is sound. It is noted that the solution methods for $\theta_{d}$ and $\theta_{p}$ are essentially those of the already verified CHEMTRN code [Miller and Benson, 1983]. In this sense, $\theta_{d}$ and $\theta_{p}$ can be regarded simply as additional basis species.

As currently formulated, the CHMTRNS code does not consider the problem of moving boundaries of regions of space occupied by solids that can undergo reversible precipitation/dissolution reactions. In the example given below, the moving boundary problem does not arise because the dissolving solid (calcite) is assumed present everywhere in the domain of transport and never dissolves completely within the period of simulated time covered by the calculations.

\section{Application}

Application of the modeling capability, fractionation of ${ }^{13} \mathrm{C}$ during transport, must await detailed geochemical characterization of investigated sites. The most realistic understanding of the complex geochemical processes is required in order to simulate the occurring phenomena correctly.

In this paper we demonstrate the new capability in a simple generic simulation. In this problem we simulate the fractionation of ${ }^{13} \mathrm{C}$ in recharge waters as they percolate through carbonate rocks. It is reported [Deines et al., 1974] 


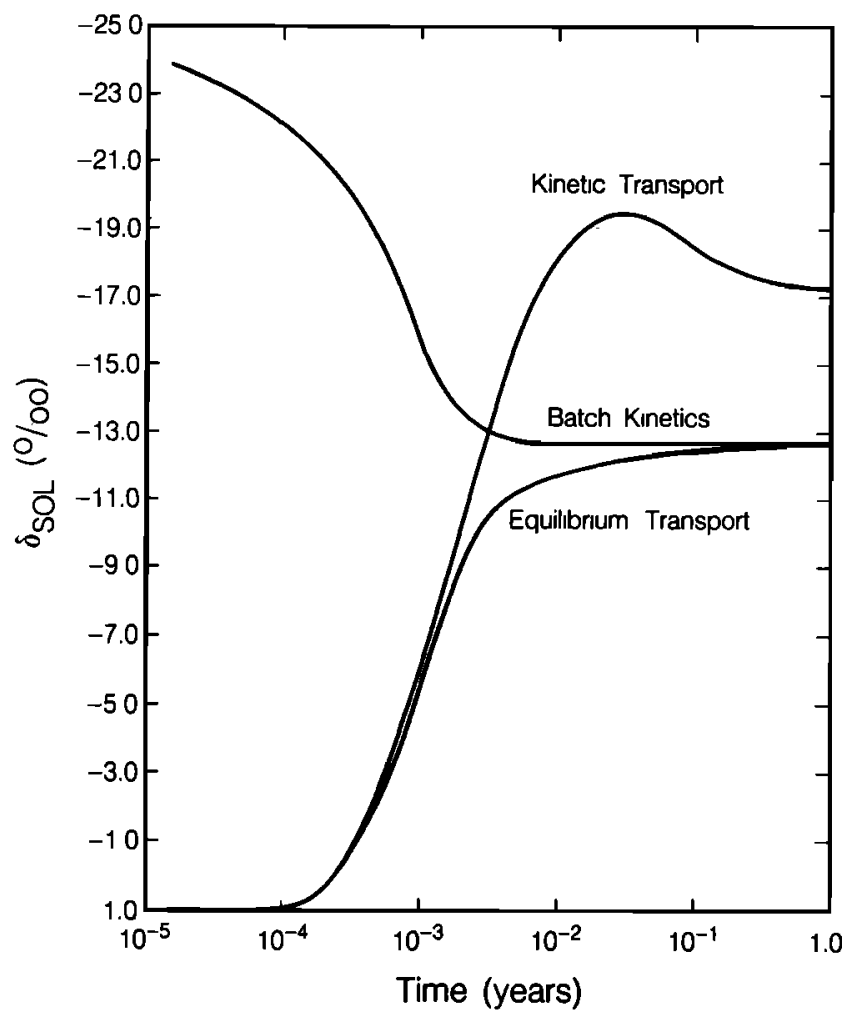

Fig. 1. Time variation of ${ }^{13} \delta_{\text {sol }}$ as a result of dilution of the carbonate species by marine calcium carbonate in various scenarios.

that for most soil waters $\delta^{13} \mathrm{C} \approx-25 \%, P_{\mathrm{CO}_{2}}$ ranges from $10^{-0.5}$ atm to $10^{-3.5}$ atm, $p H$ ranges from 4.0 to 7.5 , and specific radioactivity of ${ }^{14} \mathrm{C}=100 \%$ of the modern value. On the basis of the above data, a typical water of this nature entering marine carbonate rocks that have $\delta^{13} \mathrm{C}=0 \%$ and ${ }^{14} \mathrm{C}=0 \%$ will tend to have $\delta^{13} \mathrm{C} \approx-12.5 \%$ and ${ }^{14} \mathrm{C}=50 \%$ of modern, after equilibrium has been reached in the dissolution reaction

$$
\mathrm{CO}_{2}+\mathrm{H}_{2} \mathrm{O}+\mathrm{CaCO}_{3}(\mathrm{C}) \rightarrow \mathrm{Ca}^{2+}+2 \mathrm{HCO}_{3}^{-}
$$

The reason is evident from the mass balance of (15). However, if this reaction does not go to completion because of kinetic effects, reactive transport effects, or paucity of solid calcite in the flow path, the dilution by the ${ }^{13} \mathrm{C}$ enriched rock would lead to $\delta^{13} \mathrm{C}$ between $-25 \%$ o to $-12.5 \%$. Some of the above conditions are simulated in three hypothetical cases we have solved. Attention is drawn to the fact that for all cases initial equilibrium calculations were based on $\mathrm{CO}_{2}$ dissolution in water with $p \mathrm{H}=5$ in order to obtain the recharge water composition. For initial conditions in the spatial domain we assumed the composition of pure water at equilibrium with the calcite rock. The flow path is a onedimensional discretized space of $10 \mathrm{~m}$ length. For transport cases, flow velocity is assumed to be $1 \mathrm{~m} / \mathrm{yr}$, and the observation point is at $\boldsymbol{x}=\mathbf{0 . 0 1 2} \mathrm{m}$. This location is chosen to avoid any interference from the far boundary during the observation period. The three runs simulate batch kinetic calcite dissolution, equilibrium dissolution of calcite with transport, and kinetic dissolution with transport. The results are exhibited in Figure 1. While the first two simulations dilute the ${ }^{13} \mathrm{C}$ in the water by $50 \%$ and reduce $\delta^{13} \mathrm{C}$ to $-12.5 \%$, the kinetic transport is effective only by about $30 \%$, even after a year.

\section{Conclusions}

Governing equations for the transport and fractionation of stable ${ }^{13} \mathrm{C}$ have been formulated, and the reactive transport algorithm has been implemented in the nonequilibrium reactive chemical transport code CHMTRNS [Noorishad et al., 1987]. Applicability has been demonstrated by solving a generic problem. The new capability should add a new dimension to the investigation of groundwater evolution.

Acknowledgment. This work was supported by the Assistant Secretary for Conservation and Renewable Energy, Office of Renewable Energy Technologies, Geothermal Technology Division of the U.S. Department of Energy under contract DE-AC0376 SF00098.

\section{REFERENCES}

Deines, P., D. Langmuir, and R. S. Harmon, Stable carbon isotope ratios and existence of a gas phase in the evolution of carbonate ground waters, Geochim. Cosmochim. Acta, 38, 1147-1164, 1974.

Miller, C. W., Toward a comprehensive model of chemical transport in porous media, in Scientific Basis for Nuclear Waste Management VI, Mat. Res. Soc. Symp. Proc., vol. 15, edited by D. G. Brookins. pp., 481-488, North-Holland, New York, 1983.

Miller, C. W., and L. V. Benson, Simulation of solute transport in a chemically reactive heterogeneous system: Model development and application, Water Resour. Res., 19, 381-391, 1983.

Noorishad, N., C. L. Carnahan, and L. V. Benson, Development of the nonequilibrium reactive chemical transport code CHMTRNS, Report LBL 22361, Lawrence Berkeley Lab., Univ. of Calif., Berkeley, 1987.

Pearson, J. F., and B. B. Hanshaw, Sources of dissolved carbonate species in groundwater and their effects on carbon-14 dating, Isot. Hydrol. Proc. Symp., 1970, 271-286, 1970.

Plummer, L. N., T. M. L. Wigley, and D. L. Parkhurst, The kinetics of calcite dissolution in $\mathrm{CO}_{2}$-water system at $5^{\circ}$ to $60^{\circ} \mathrm{C}$ and 0.0 to $1.0 \mathrm{~atm} \mathrm{CO} ;$ Am. J. Sci., 278, 1683-1699, 1978.

Wigley, T. M. L., Carbon-14 dating from closed and open systems, Water Resour. Res., II(2), 324-328, 1975.

L. V. Benson, U.S. Geological Survey, Denver, CO 80225.

C. L. Carnahan and J. Noorishad, Earth Sciences Division, Lawrence Berkeley Laboratory, 1 Cyclotron Road, Berkeley, CA 94720.

(Received March 2, 1988;

revised January 19, 1989;

accepted January 27,1989 .) 